\title{
INFLUÊNCIA DO JEJUM ALIMENTAR NA MORTALIDADE, PERDA DE PESO VIVO, FRATURAS, HEMATOMAS E CONTAMINAÇÃO DE CARCAÇAS EM ABATEDOURO DE FRANGOS
}

(Influence of feed withdrawal on mortality, body weight loss, fractures, bruises and contamination of carcasses in poultry slaughterhouse)

\author{
Rodrigo Félix Lana ${ }^{1}$, Adriano França da Cunha ${ }^{1}$, Ricardo Félix Lana ${ }^{1}$, Leonardo Faria Santos ${ }^{1}$, \\ Fabiana Rocha Araújo², Marcelo Dias da Silva ${ }^{1}$
}

\begin{abstract}
1 União de Ensino Superior de Viçosa, Minas Gerais, Brasil, ${ }^{2}$ Universidade Federal de Viçosa, Minas Gerais, Brasil. *Correspondência: adrianofcunha@hotmail.com.br
\end{abstract}

RESUMO: O objetivo do trabalho foi avaliar a influência do jejum alimentar em diferentes etapas ante-mortem na ocorrência de mortes, perda de peso vivo, contaminação e condenação de carcaças por fraturas e hematomas de aves em abatedouro de frangos de Minas Gerais. Foram avaliados 1.072.491 frangos distribuídos em 312 lotes/caminhões. Foram determinados os períodos de retirada da ração até o início da apanha, da apanha, de transporte, de espera das aves no pátio do abatedouro até o momento do abate e de todo o jejum. O peso vivo das aves foi obtido em granjas e a mortalidade e perda de peso vivo foram determinadas assim que os animais chegaram ao abatedouro. Carcaças com fraturas, hematomas e contaminadas por fezes/bile foram quantificadas no abatedouro. $\mathrm{O}$ jejum durante a espera dos animais no pátio do abatedouro antes do abate influenciou $(P<0,05)$ a contaminação das carcaças por fezes/bile e a perda de peso vivo dos frangos. $O$ jejum durante 0 transporte influenciou $(P<0,05)$ a mortalidade de frangos ao chegarem ao abatedouro. $O$ jejum durante a retirada da ração até a apanha influenciou $(P<0,05)$ a perda de peso vivo e a ocorrência de fraturas e hematomas nos frangos. Todo o período de jejum influenciou $(P<0,05)$ a perda de peso vivo dos frangos. Portanto, a mortalidade, fraturas, hematomas, perda de peso vivo de frangos e a contaminação de carcaças estão diretamente relacionados com o jejum em diferentes etapas ante-mortem, o que pode causar prejuízos para a indústria avícola.

Palavras-chave: abate; ave; bem-estar; condenação; transporte 
ABSTRACT: The objective this study was to evaluate the influence of feed withdrawal in different ante-mortem stages in the occurrence of death, body weight loss, contamination and condemnation of carcasses occasioned by fractures and bruising of the birds in the poultry slaughterhouse of Minas Gerais. They were evaluated 1,072,491 poultry distributed in 312 lots/trucks. It was determined period of feed removal until the start of catching, catching, transport, waiting for the poultry at the slaughterhouse courtyard until the slaughter and the all feed withdrawal. The body weight of the poultry was obtained on farms and mortality and body weight loss were determined once the animals arrived at the abattoir. Carcasses with fractures, bruises and contaminated by faeces/bile were quantified in slaughterhouse. Withdrawal during standby of animals at the slaughterhouse courtyard before slaughter influenced $(P<0.05)$ contamination of carcasses by faeces/bile and the live weight loss of poultry. Withdrawal during transport influenced $(P<0.05)$ mortality of poultry upon arrival at the slaughterhouse. Withdrawal during the feed removal until the catching influenced $(P<0.05)$ body weight loss and the occurrence of fractures and bruises in poultry. The withdrawal period influenced $(\mathrm{P}<0.05)$ body weight loss of poultry. Therefore, mortality, fractures, bruises, body weight loss of poultry and contamination of carcasses are directly related to withdrawal in different ante-mortem stages, which can cause damage to the poultry industry. 


\section{INTRODUÇÃO}

O Brasil é o maior exportador e segundo maior produtor mundial de carne de frango (USDA, 2017). Apesar da importância da produção de frangos no setor avícola nacional, a qualidade da carne é um dos fatores mais preocupantes, principalmente em relação aos transtornos que o manejo pré-abate podem causar no produto final. $O$ estresse das aves durante esta etapa determina o nível elevado de perdas por mortalidade na chegada dos animais ao matadouro (Rui et al., 2011).

Qualquer lesão na carcaça originada durante o manejo pré-abate é passível de condenação no matadourofrigorífico, o que ocasiona perdas na produção de frangos. Uma perda significativa ocorre por meio das condenações de peito devido a hematomas e lesões de grande impacto econômico. Isto mostra que a influência do manejo pré-abate na qualidade e rendimento do produto final deve ser avaliada (Abreu e Abreu, 2002; Lima et al., 2014).

Outros motivos de condenações durante a inspeção de carnes de aves são contusões, fraturas, caquexia, dermatose, artrite, celulite, aerossaculite, salpingite, ascite, neoplasia e carcaças com aspecto repugnante, como coloração e odores anormais (Mendes e Komiyama, 2011). A contaminação das carcaças pelo conteúdo digestivo pode acontecer durante 0 abate e evisceração de frangos, principalmente se 0 trato intestinal do animal estiver cheio devido ao jejum inadequado (Mendes, 2001).

O bom manejo pré-abate inclui a avaliação do jejum, período de seis a oito horas em que a ração é afastada dos animais, mas a água ainda é fornecida (Brasil, 1998). O jejum possui a função de evitar vômitos durante o transporte das aves ao abatedouro e diminuir os riscos de contaminação da carne durante a evisceração do animal abatido. Além disto, tem-se menores perdas com a ração, já que esta não é metabolizada momentos antes do abate e é perdida durante a evisceração (Mendes, 2001; Schettino et al., 2006).

$\mathrm{Na}$ avicultura industrial, há uma preocupação quanto ao período ideal de jejum, pois procura-se atingir suas funções, mas sem afetar o rendimento de carcaça e a perda de peso vivo. Os pesquisadores definem o período de oito a doze horas como o tempo ideal para reduzir a incidência de contaminação, condenações e não afetar 0 rendimento de carcaça (Assayag Jr. et al., 2005; Costa et al., 2007). Por outro lado, o jejum prolongado pode causar enfraquecimento da parede intestinal e vesícula biliar, aumentando o risco de rompimento durante a evisceração (Rui et al., 2011).

O esquema de abate varia muito entre os matadouros, sendo constituída de etapas como preparo do galpão e retirada da ração, apanha das aves, transporte ao abatedouro e espera do caminhão na plataforma de desembarque antes do abate. Às vezes, o período total de jejum acaba sendo prolongado em razão da espera do desembarque (Northcutt et al., 1997; Denadai et al., 2002; Castro et al., 2008). Portanto, o objetivo deste trabalho foi avaliar a influência do jejum alimentar em diferentes etapas antemortem na ocorrência de mortes, fraturas, hematomas, perdas de peso vivo de aves e contaminação de carcaças durante 0 abate em abatedouro de frangos.

\section{MATERIAL E MÉTODOS}

$O$ experimento foi realizado em um abatedouro de frangos localizado em Minas Gerais, nos meses de agosto e setembro de 2014. O estabelecimento abatia em média 152.000 aves por dia, 
em uma velocidade média de 9.000 aves por hora, produzindo em torno de 340 toneladas de carne por dia, sendo destinada para o mercado interno e externo. No entanto, possuía histórico de grande número de aves condenadas por contaminação, fraturas e hematomas na linha do fluxo de abate.

Ao longo do experimento, foram avaliados 1.072.491 frangos distribuídos em 312 lotes/caminhões. As granjas que abasteciam 0 abatedouro estavam localizadas no raio de no máximo 90 $\mathrm{Km}$. Os frangos foram transportados das granjas aos abatedouros por meio de caixas $(0,83 \mathrm{~m}$. de comprimento $\times 0,59 \mathrm{~m}$. de largura $\times 0,30 \mathrm{~m}$. de altura) em caminhões com capacidade para 520 caixas.

Para determinar o tempo de jejum das aves, foram definidos os tempos da retirada da ração até o início da apanha (T1), da apanha (T2), de transporte (T3), e de espera do caminhão no pátio do abatedouro até o momento do abate (T4). Os tempos foram obtidos de forma estratificada, pois as aves poderiam sofrer intensidades diferentes de estresse em cada momento. Todos os tempos foram somados para se ter o tempo total do jejum (Total).

Para determinação das perdas percentuais de peso vivo das aves durante o jejum, foram obtidos o peso médio vivo das aves em cada granja e o peso médio vivo assim que os animais chegaram ao abatedouro. $O$ peso das carcaças foi obtido para expressar o rendimento de carcaça em porcentagem. A mortalidade foi avaliada por meio do número de animais que chegaram mortos ao abatedouro pelo número total de animais que chegaram, sendo expressa em porcentagem.

As peças anatômicas condenadas por fraturas e hematomas foram quantificadas na linha de inspeção $C$, na qual é realizado 0 exame externo da carcaça (Brasil,
1998). Foram consideradas fraturas e hematomas passíveis de condenação total ou parcial da carcaça. A porcentagem de peças condenadas por fraturas e hematomas foi determinada pela quantidade de aves vivas que chegaram ao abatedouro.

As carcaças contaminadas por fezes e/ou bile foram contabilizadas após a eventração, na linha de inspeção B e C (Brasil, 1998), e após evisceração, durante a reinspeção das carcaças no abatedouro. Foram consideradas as contaminações em áreas extensas da carcaça, sujeitas a condenação parcial ou total da carcaça. A porcentagem de carcaças contaminadas foi determinada pela quantidade de aves vivas que chegaram no caminhão.

As temperaturas foram mensuradas no ambiente do abatedouro e no interior das caixas colocadas no caminhão por meio de termômetro. A umidade relativa do ar também foi mensurada no abatedouro. Tanto a temperatura quanto a umidade do ar foram mensuradas por meio de psicrômetro digital Modelo PSCD-8010 (Sonambra Ltda., Amparo, Brasil).

Os resultados foram discutidos de forma descritiva e submetidos ao teste de normalidade Shapiro-Wilk. Em seguida, foram submetidos à correlação de Pearson ao nível de $5 \%$ de significância, utilizando software Stata 12.0 (StataCorp LP, Texas, USA).

\section{RESULTADOS E DISCUSSÃO}

Observou-se que o número médio de frangos por caminhão foi de $3.437,5$ (Tabela 1). Esse valor varia de acordo com o número de frangos por caixa, o que no abatedouro pesquisado foi em média de 6,86 frangos. Deve-se levar em consideração o sexo, peso das aves, clima e distância do aviário ao abatedouro para definir o número de 
aves colocadas em cada caixa (Nijdam et al., 2004; Silva e Vieira, 2010).

No transporte das aves ao abatedouro pesquisado, $20,17 \mathrm{Kg}$ de frangos vivos eram colocados nas caixas. Mendes (2004) relatou que a quantidade de aves em caixas tradicionais observadas durante 0 presente experimento, deve permitir 22 $\mathrm{Kg}$ de frango/caixa ou $0,020 \mathrm{~m}^{2} / \mathrm{Kg}$ de frango no verão e $0,024 \mathrm{~m}^{2} / \mathrm{Kg}$ no inverno.

Tabela 1 - Características de abate, tempo de jejum, peso das aves e climáticas em um abatedouro de frangos.

\begin{tabular}{lccc}
\multicolumn{1}{c}{ Parâmetro } & Valor & $\begin{array}{c}\text { Desvio } \\
\text { Padrão }\end{array}$ & $\begin{array}{c}\text { Coeficiente } \\
\text { de Variação } \\
(\%)\end{array}$ \\
\hline Número médio de frangos/caminhão & $3.437,5$ & 343,6 & 9,99 \\
Peso médio de frangos (Kg) & 2,94 & 0,19 & 6,66 \\
Número médio de frangos/caixa & 6,86 & 0,56 & 8,19 \\
Relação macho/fêmea & $50,2: 49,8$ & - & - \\
Tempo médio do jejum à apanha (min.) & 459,6 & 152,6 & 33,20 \\
Tempo médio de apanha (min.) & 68,9 & 57,6 & 83,64 \\
Tempo médio de transporte (min.) & 72,9 & 30,95 & 42,48 \\
Tempo médio de espera no abatedouro (min.) & 203,8 & 64,39 & 31,60 \\
Tempo médio de jejum total (min.) & 805,0 & 169,13 & 21,00 \\
Mortalidade ao abatedouro (\%) & 0,31 & 0,25 & 81,81 \\
Contaminação de carcaça/caminhão (\%) & 5,33 & 3,38 & 63,56 \\
Fraturas/hematomas (\%) & 3,01 & 2,01 & 66,79 \\
Perda de peso vivo médio ao jejum (\%) & 2,34 & 0,56 & 24,53 \\
Rendimento de carcaça (\%) & 80,0 & 1,65 & 2,06 \\
Temperatura média do ambiente $\left({ }^{\circ} \mathrm{C}\right)$ & 21,8 & 5,2 & 109,00 \\
Temperatura média do caminhão $\left({ }^{\circ} \mathrm{C}\right)$ & 22,3 & 4,3 & 106,88 \\
Umidade média do ar $(\%)$ & 63,8 & 8,7 & 132,97 \\
\hline
\end{tabular}

Somado aos tempos médios da retirada da ração até a apanha $(459,6$ minutos), de apanha (68,9 minutos), de transporte (72,9 minutos) e de espera das aves nos caminhões até o momento do abate (203,8 minutos), o tempo médio total de jejum foi de 805,0 minutos. Isto equivalente a mais de 13 horas de jejum, o que expõem as aves a um elevado nível de estresse (Schettino et al., 2006).

A mortalidade média no frigorífico foi de $0,31 \%$, índice atualmente aceitável pelos abatedouros no Brasil. Segundo Ritz (2003), as perdas por death on arrivals (DOA's) podem ultrapassar $1 \%$, sendo que $40 \%$ das perdas são em função do estresse térmico. No presente experimento, as temperaturas médias ambientais no abatedouro e no interior das caixas mantidas no caminhão não foram consideradas altas.

A temperatura média do ambiente do abatedouro foi de $21,8^{\circ} \mathrm{C}$ e nas caixas do caminhão foi de $22,3^{\circ} \mathrm{C}$, enquanto que a umidade relativa média do ar foi de 63,8\%. De acordo com Aksit et al. (2006), as aves não apresentam alterações fisiológicas quando transportadas entre 15 e $22^{\circ} \mathrm{C}$. O caminhão em movimento proporciona uma relativa ventilação, favorecendo a redução da carga térmica gerada pelas aves. Entretanto, com 0 caminhão parado durante a espera, a sensação térmica dos frangos aumenta devido a produção de calor e vapor d'água dos animais.

Observou-se que a porcentagem média de contaminação das carcaças por fezes e/ou bile foi de 5,33\%, enquanto que porcentagem de fraturas e hematomas foi de 3,01\%. Segundo Ferreira et al. (2012), as principais causas de condenação em matadourosfrigoríficos de frangos sob inspeção federal no Rio Grande do Sul foram relacionadas à contaminação da carcaça, contusões e fraturas.

A perda de peso vivo médio ao jejum foi de 2,34\%. O aumento do período de jejum aumenta a perda de peso das aves. Além do esvaziamento intestinal, a desidratação ocorrida nos músculos durante o transporte também influencia a perda de peso das aves (Denadai et al., 2002). A intensidade da perda de peso está relacionada com outros fatores, tais como: tamanho das aves, condições de transporte e temperatura do ambiente de espera para o abate (Castro et al., 2008).

O tempo de transporte (T3) influenciou $(P<0,05)$ as taxas de mortalidade das aves, sendo que quanto maior o tempo maior a mortalidade (Tabela 2). Os frangos ficam expostos a uma variedade de agentes estressores durante o transporte como aceleração, 
vibração, impactos, jejum alimentar e hídrico, mistura social, perturbações e ruídos, além do microambiente térmico que se forma entre as aves (Bianchi et al., 2005; Simões et al., 2009). Tais fatores podem ter influenciado a mortalidade observada, pois se intensificam com a demora no transport.

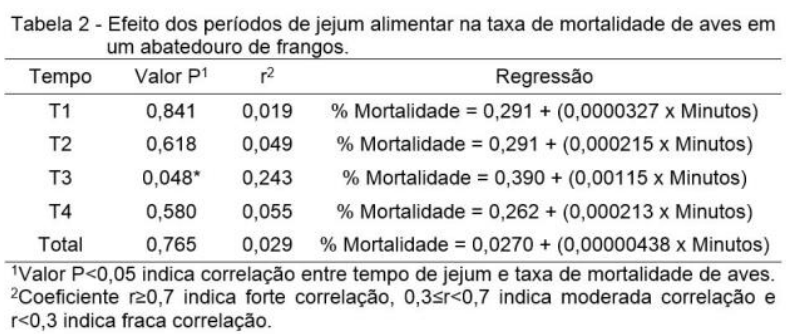

Apesar da taxa de mortalidade de aves ter sido baixa e as temperaturas dentro das caixas estarem adequadas, é necessário melhor planejamento da viagem durante 0 transporte para minimizar o tempo de transporte. Outros fatores como direção harmônica, distância das granjas ao abatedouro e temperatura ambiente devem ser levados em consideração. Vale ressaltar que o frio também pode causar estresse nos animais, sobretudo quando intensificado durante a movimentação do caminhão (Silva et al., 2007; Rui et al., 2011).

Observou-se que o elevado tempo de espera dos animais no pátio do abatedouro até o momento do abate (T4) influenciou $(\mathrm{P}<0,05)$ o aumento das taxas de contaminação das carcaças por fezes e/ou bile durante a eventração e evisceração das aves (Tabela 3). Segundo Kirov (1993), a contaminação é um dos maiores problemas enfrentados pelas indústrias que utilizam eventração mecânica e sistemas automatizados, sistema utilizado pelo abatedouro pesquisado. Este fato é decorrente da perfuração do sistema digestivo no momento da extração das vísceras da ave, sobretudo se estiverem fragilizadas. Apesar do tempo total de jejum não ter apresentado correlação com a contaminação de carcaças, Northcutt et al. (1997) afirmaram que se o período de jejum alimentar for longo, os intestinos se fragilizam e a incidência de rompimento durante a evisceração tende a aumentar. Como a espera das aves no pátio antes do abate (T4) é a etapa final do jejum das aves, a fragilidade das alças talvez aconteça com maior intensidade neste período.

Tabela 3 - Efeito dos períodos de jejum alimentar na ocorrência de contaminação de \begin{tabular}{cccc} 
& carcaça de aves por fezes e/ou bile em um abatedouro de frangos. \\
\hline Tempo & Valor $\mathrm{P}^{1}$ & $\mathrm{r}^{2}$ & Regressão \\
\hline T1 & 0,411 & 0,081 & $\%$ Contaminação $=6,157+(0,00181 \times$ Minutos $)$ \\
T2 & 0,991 & 0,001 & $\%$ Contaminação $=5,331+(0,0000684 \times$ Minutos $)$ \\
T3 & 0,450 & 0,075 & $\%$ Contaminação $=5,923+(0,00818 \times$ Minutos $)$ \\
T4 & $0,024^{*}$ & 0,321 & $\%$ Contaminação $=2,963+(0,0116 \times$ Minutos $)$ \\
Total & 0,971 & 0,003 & $\%$ Contaminação $=5,384+(0,0000711 \times$ Minutos $)$ \\
\hline
\end{tabular} ${ }^{1}$ Valor $\mathrm{P}<0,05$ indica correlação entre tempo de jejum e porcentagem de carcaça de
aves contaminadas. ${ }^{2}$ Coeficiente $r \geq 0,7$ indica forte correlação, $0,3 \leq r<0,7$ indica aves contaminadas. ${ }^{2}$ Coeficiente $r \geq 0,7$ indica fort
moderada correlação e $r<0,3$ indica fraca correlação.

O elevado tempo da retirada da ração até a apanha das aves (T1) influenciou $(P<0,05)$ a ocorrência de fraturas e hematomas (Tabela 4) devido à possível elevação do estresse, o que culmina em maiores movimentações bruscas das aves durante a apanha. Mendes (2004) relata a origem das condenações por fraturas e hematomas está relacionada à todo o manejo das aves durante a criação, apanha, transporte e abate. As perdas e condenações ao abate podem se intensificar com o alto peso das aves, sobretudo durante o preparo dos galpões para apanha das aves.

\footnotetext{
Tabela 4 - Efeito dos periodos de jejum alimentar na ocorrência de fraturas e \begin{tabular}{cccc}
\multicolumn{4}{c}{ hematomas de aves em um abatedouro de frangos. } \\
\hline Tempo & Valor $\mathrm{P}^{1}$ & $\mathrm{r}^{2}$ & Regressão \\
\hline T1 & $0,042^{*}$ & 0,268 & $\%$ Fratura/Hematoma $=4,032+(0,00222 \times$ Minutos $)$
\end{tabular} $\begin{array}{llll}\text { T1 } & 0,042^{*} & 0,268 & \% \text { Fratura/Hematoma }=4,032+(0,00222 \times \text { Minutos }) \\ \text { T2 } & 0,358 & 0,091 & \% \text { Fratura/Hematoma }=3,231+(0,00318 \times \text { Minutos })\end{array}$ T3 $0,957 \quad 0,005 \quad \%$ Fratura/Hematoma $=3,038+(0,000347 \times$ Minutos $)$ T4 $0,432 \quad 0,078 \quad \%$ Fratura/ $/$ Hematoma $=2,516+(0,00244 \times$ Minutos $)$ Total $\quad 0,118 \quad 0,154 \quad \%$ Fratura/ $/$ Hematoma $=4,489+(0,00183 \times$ Minutos $)$ ${ }^{1}$ Valor $\mathrm{P}<0,05$ indica correlação entre tempo de jejum e porcentagem de fraturas $\mathrm{e}$ hematomas de aves. ${ }^{2}$ Coeficiente $r \geq 0,7$ indica forte correlação, $0,3 \leq r<0,7$ indica moderada correlação e $r<0,3$ indica fraca correlação.
}

Mendes (2001) relataram fatores como o método de apanha, tempo de transporte, tempo de espera, tipos de caixas de transporte, a densidade por 
gaiola, período de apanha, idade, sexo e temperatura como parâmetros que influenciam as lesões de aves. No presente estudo, todos estes fatores foram randomizados, exceto o tempo de transporte e espera, os quais não apresentaram correlação com as condenações.

Observou-se que a perda de peso vivo das aves foi influenciada $(P<0,05)$ pelos tempos de retirada da ração até a apanha (T1), tempo de espera das aves no abatedouro (T4) e tempo total de jejum (Tabela 5). Após o início da retirada do alimento e água, inicia-se os processos de perda do conteúdo intestinal e de desidratação da carcaça, sendo que estes processos são lineares à medida que aumenta a duração do jejum (Assayag Jr. et al., 2005)

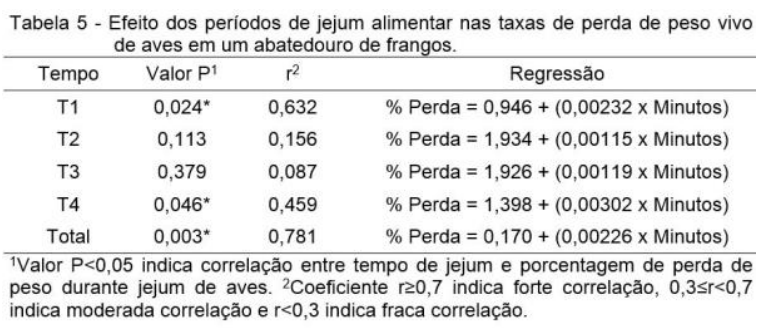

Vegro e Rocha (2007) verificaram que as perdas de peso vivo e as taxas de absorção de água pela carcaça aumentaram gradualmente com 0 aumento dos tempos de jejum, porém os rendimentos de carcaça não foram afetados pelos períodos de restrição. Entretanto, Lyon et al. (1991) relataram que a perda de peso aumentou linearmente com o aumento do tempo de jejum, o que afetou linearmente 0 rendimento de carcaça, antes e após o resfriamento.

Denadai et al. (2002) observaram que não há perdas significativas no rendimento de carcaça de frangos de corte quando o jejum é de 16 horas ou menos, sendo que isso só ocorre quando o período de jejum é de 24 horas ou mais. Apesar do rendimento de carcaça não ter sido avaliado no presente estudo, alguns lotes de aves passaram por períodos prolongados de jejum, principalmente por causa da espera para serem abatidas, o que afetou a perda de peso das aves ao abate e, portanto, pode ter afetado o rendimento de carcaça devido ao déficit energético ao longo do período.

\section{CONCLUSÕES}

As taxas de mortalidade, fraturas, hematomas, perdas de peso vivo de frangos e contaminação de carcaças durante o abate são influenciadas pelo jejum alimentar em diferentes etapas ante-mortem, o que pode trazer grandes prejuízos para a indústria avícola. Medidas de manejo mais adequadas nas granjas e administração eficiente a fim de reduzir o tempo da retirada da ração até 0 abate podem reduzir a mortalidade e as perdas post-mortem. Para isto, o acompanhamento de profissionais como médico veterinário é imprescindível durante essas etapas.

\section{REFERÊNCIAS}

ABREU, V.M.N.; ABREU, P.G. Qualidade de carcaça e o manejo na produção. Revista Avicultura Industrial, v.5, n.93, p.12-14, 2002.

AKSIT, M.; YALÇIN, S.; OZKAN, S. et al. Effects of temperature during rearing and crating on stress parameters and meat quality of broilers. Poultry Science, v.85, n.11, p.1867-1874, 2006.

ASSAYAG JR., M.S.; PEDROSO, A.C.; FRANCO, S.G. et al. Efeito da duração do jejum pré-abate sobre peso corporal de frangos de corte aos 45 dias de idade. Brazilian Journal of Veterinary Research and Animal Science, v.42, n.3, p.188-192, 2005.

BIANCHI, M.; PETRACCI, M.; CAVANI, C. Effects of transport and lairage on 
mortality, liveweight loss and carcass quality in broiler chickens. Italian Journal of Animal Science, v.4, n.2, p.516-518, 2005.

BRASIL, Ministério da Agricultura e do Abastecimento. Portaria $n^{\circ} 210$ de 10 de novembro de 1998. Aprova o Regulamento Técnico de Inspeção Tecnológica e Higiênico-sanitária de Carnes de Aves. Diário Oficial da União, Brasília, seção 1, p.226, 26-de novembro de 1998.

CASTRO J.B.J.; CASTILLO C.J.C.; ORTEGA E.M.M. Jejum alimentar na qualidade da carne de frangos de corte criados em sistema convencional. Ciência Rural, v.38, n.2, p.470-476, 2008.

COSTA, F.M.R.; PRATA, L.F.; PEREIRA, G.T. Influência das condições de pré-abate na incidência de contusões em frangos de corte. Veterinária e Zootecnia, v.14, n.2, p.234-245, 2007.

DENADAI, J.C.; MENDES, A.A.; GARCIA, R.G. et al. Efeito da duração do período de jejum pré-abate sobre rendimento de carcaça e a qualidade da carne do peito de frangos de corte. Revista Brasileira de Ciência Avícola, v.4, n.2, p.101-109, 2002.

FERREIRA, T.Z.; SESTERHENN, R.; KINDLEIN, L. Perdas econômicas das principais causas de condenações de carcaças de frangos de corte em Matadouros-Frigoríficos sob Inspeção Federal no Rio Grande do Sul, Brasil. Acta Scientiae Veterinariae, v.40, n.1, p.1-6, 2012.

KIROV, S.M. The public health significance of Aeromonas spp. in foods. International Journal of Food
Microbiological, v.20, n.4, p.179-198, 1993.

LIMA, K.C.; MASCARENHAS, M.T.V.L.; CERQUEIRA, R.B. Técnicas operacionais, bem estar animal e perdas econômicas no abate de aves. Archives of Veterinary Science, v.19, n.1, p.3845, 2014.

MENDES, A.A. Controle de perdas e condenações no abatedouro. Revista AveWorld, v.1, n.6, p.16-25, 2004.

MENDES, A.A. Jejum pré-abate em frangos de corte. Revista Brasileira de Ciência Avícola, v.3, n.3, p.199-209, 2001.

MENDES, A.A.; KOMIYAMA, C.M. Estratégias de manejo de frangos de corte visando qualidade de carcaça e carne. Revista Brasileira de Zootecnia, v.40, p.352-357, 2011.

NIJDAM, E.; ARENS, P.; LAMBOOIJ, E. et al. Factors influencing bruises and mortality of broilers during catching, transport, and lairage. Poultry Science, v.83, n.9, p.1610-1615, 2004.

NORTHCUTT, J.K.; SAVAGE, S.I.; VEST, L. R. Relationship between feed withdrawal and viscera condition of broilers. Poultry Science, v.76, n.2, p.410-414, 1997.

RITZ, C.W. Reducing caching and livehaul DOA's. Poultry Digital Online, v.4, n.1, p.1-14, 2003.

RUI, B.R.; ANGRIMANI, D.S.R.; SILVA, M.A.A. Pontos críticos no manejo préabate de frango de corte: jejum, captura, carregamento, transporte e tempo de espera no abatedouro. Ciência Rural, v.41, n.7, p.1290-1296, 2011.

SCHETTINO, D.N.; CANÇADO, S.V.; BAIÃO, N.C. et al. Efeito do período de 
jejum pré-abate sobre o rendimento de carcaça de frango de corte. Arquivo Brasileiro de Medicina Veterinária e Zootecnia, v.58, n.5, p.918-924, 2006.

SILVA, I.J.O.; VIEIRA, F.M.C. Ambiência animal $e$ as perdas produtivas no manejo pré-abate: o caso da avicultura de corte brasileira. Arquivos de Zootecnia, v.59, p.113131, 2010.

SILVA, N.A.M.; BARBOSA FILHO, J.A.D.; SILVA, C.J.M. et al. Avaliação do

estresse térmico em condição simulada de transporte de frangos de corte. Revista Brasileira de Zootecnia, v.36, n.4, p.1126-1130, 2007.

SIMÕES, G.S.; OBA, A.; MATSUO, T. et al. Vehicle thermal microclimate evaluation during Brazilian summer broiler transport and the occurrence of PSE (Pale, Soft, Exudative) meat. Brazilian Archives Biology and Technology, v.52, p.195-204, 2009.

USDA, United States Department of Agriculture. Livestock and Poultry: World Markets and Trade. Foreign Agricultural Service: USDA, 2017. 27p. Disponível em:https://apps.fas.usda.gov/psdonline/ circulars/livestock_poultry.pdf Acesso: 22 de março de 2018. 